cannot exist partly literate and partly illiterate.' The task of fundamental education, however, was not merely to achieve literacy, but to enable men and women to live fuller lives, to develop their resources, and to take their places in the modern world; its aim was education for better living. It was important to be clear about the aims of fundamental education; the techniques would take care of themselves. Mr. Grierson referred to the pilot projects organized by U.N.E.S.C.O. in different areas with a view to gathering information, comparing results, and making the excellencies of each achievement available for the benefit of others. In pointing out that the citizens of the United Kingdom had a special interest in fundamental education, Mr. Grierson alluded to the work done by the Soviet Union in eliminating illiteracy and carrying out education in 200 vernacular languages, of which 90 were taught in schools. Referring to the Secretary of State's words in his opening address about the use of films in presenting European culture to African peoples, Mr. Grierson suggested that an equally important objective was the production of films in Africa by Africans and for Africans. The Cinema as an educational agency should not be considered in isolation; he would like to see in Britain a School of Colonies where a body of knowledge relating to all aspects of Colonial culture and development could be brought together. He would also like to see the development of the British Colonial Film Unit, with considerable decentralization and an extension of managerial and research functions to Africans; finally, he advocated a school of experimental cinema relating to Africa as a whole.

\title{
East Africa Literature Committee
}

FollowiNg the recommendations made by Mrs. Elspeth Huxley relating to the demand for literature among Africans in East Africa, the East African governments have agreed in principle to the establishment of an organization with headquarters in Nairobi to stimulate the production of books and other publications for the African populations of Kenya, Uganda, Tanganyika, and Zanzibar. In the first instance attention is to be concentrated on production in Swahili and Ganda, except in the case of school text-books; the question of providing literature in other East African languages and for Asians is to be considered later. Separate sections will deal with text-books, periodicals, general literature, distribution and business management, and libraries. The production of a popular magazine in English, Swahili, Ganda, Gang-Dholuo, and Kikuyu will be considered. It is proposed that the organization should stimulate the production of cheap books in Swahili and other East African languages on a variety of general subjects such as civics, biography, travel, local history, current events, \&c. It is also proposed that a central library system should be developed to which existing and proposed local libraries could be linked under the supervision of a trained librarian.

\section{Uganda African Literature Committee}

THis Committee was set up by the Chief Secretary, under the chairmanship of Mr. Snoxall, Deputy Director of Education. It is planned on a wide basis to be a channel for publishing approved works and to be a link between authors, publishers, and printers. It is prepared to advise writers on suitable books for translation, to criticize original books, and to explain the technicalities of publication. Its activities include the development of literacy and the establishment of a library service; in connexion with the latter, it has compiled and distributed instructions for librarians and a cataloguing system. The committee includes representatives of missions, government, commerce, and of Makerere College. 